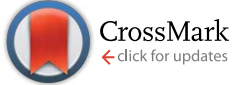

Cite this: RSC Adv., 2017, 7, 5136
Received 29th September 2016 Accepted 9th December 2016

DOI: 10.1039/c6ra24218a

www.rsc.org/advances

\section{Exploratory catalyst screening studies on the liquefaction of model humins from $\mathrm{C} 6$ sugars $\dagger$}

\begin{abstract}
Y. Wang, S. Agarwal, Z. Tang and H. J. Heeres*
A catalyst screening study is reported on the liquefaction of humins, the solid byproducts from C6 sugar biorefineries for levulinic acid and 5-hydroxymethylfurfural production. Experiments were carried out in a batch reactor using an artificial model of humin derived from glucose with isopropanol (IPA) as the solvent at $400{ }^{\circ} \mathrm{C}$ for a $3 \mathrm{~h}$ batchtime. Initial studies using noble metal catalysts ( $\mathrm{Rh}, \mathrm{Pt}, \mathrm{Pd}, \mathrm{Ru}$ ) on a carbon support revealed that Pt was the best catalyst in terms of humin conversion (77\%) and amounts of alkylphenolics and aromatics in the product oil (GCxGC-FID). Subsequent support screening studies $\left(\mathrm{TiO}_{2}, \mathrm{ZrO}_{2}, \mathrm{CeO}_{2}\right)$ were performed using $\mathrm{Pt}$ as the active metal and the results were compared with $\mathrm{Pt} /$ C. Detailed liquid product analysis (GPC, GC-MS, GCxGC) including blank reactions in the absence of humins revealed that the humins are mainly converted to monomeric alkylphenolics and aromatics oligomers (GPC) and (GC). IPA was shown not to be inert and is converted to acetone and hydrogen, and the latter is the hydrogen source for the various metal catalysed hydrogenolysis and hydro(deoxy) genation reactions. In addition, acetone is converted to aldolcondensation products (like methylisobutylketone, MIBK) and hydrogenation products derived thereof. The best results were obtained with $\mathrm{Pt} / \mathrm{C}$ when considering humin conversion. However, $\mathrm{Pt} / \mathrm{CeO}_{2}$ was shown to be more attractive when considering the amounts of alkylphenolics in the product oils ( $20.4 \mathrm{wt} \%$ based on humin intake).
\end{abstract}

\section{Introduction}

Ligno-cellulosic biomass is regarded as an important alternative for fossil resources for the production of biobased products. ${ }^{\mathbf{1 - 1 5}}$ For instance, it has been shown that the cellulose and hemicellulose fraction may be transformed into platform chemicals using either biochemical or metal/Brönsted acid catalysed transformations. ${ }^{\mathbf{1 - 5 , 1 6 - 1 8}}$ Well known examples of platform chemicals are levulinic acid (LA) and 5-hydroxymethylfurfural (HMF) and both have been shown to be attractive intermediates for a large range of interesting products with high application potential. ${ }^{19-24}$ Example are 2,5-furanedicarboxylic acid, a monomer for renewable polymers, and acetals from levulinic acid. ${ }^{\mathbf{1 2}}$ However, the conventional synthetic methodology to produce LA and HMF in water using a mineral acid as the catalyst inevitably leads to the formation of solid byproducts known as humins. These not only cause blocking of pipes and other process equipment but also lower the carbon efficiency of the conversions considerably., ${ }^{1,25,26}$ In some cases, humin yields as high as $40 \%$ based on feed intake have been reported. ${ }^{27,28}$

Chemical Engineering Department, ENTEG, University of Groningen, Nijenborg 4, 9747 AG Groningen, The Netherlands. E-mail: h.j.heeres@rug.nl

$\dagger$ Electronic supplementary information (ESI) available. See DOI: $10.1039 / \mathrm{c} 6 \mathrm{ra} 24218 \mathrm{a}$
To reduce humin formation and/or to obtain value-added chemicals from humin, a good understanding of the molecular structure of humin is of high importance. Unfortunately detailed information was limited till several years ago because of its complex, highly condensed structure and its low solubility in conventional organic solvents, which hamper analysis by techniques such as NMR. However, the rapid developments in the field of hydrothermal carbonisation during the last decade has led to further insights. The molecular structure of the main product of this process, hydrothermal carbons (HTC), have been investigated in detail. ${ }^{29-32}$ HTC are typically obtained by heating various lignocellulosic biomass sources in water at elevated temperatures and pressures. In this respect, the structure may differ from typical humins obtained by a conventional LA and HMF synthesis as strong Bronsted acids are used here, which may have a major impact on the composition and molecular structure of the humins formed.

A limited number of characterisation studies have been reported for humins from monomeric sugars using acids as the catalysts. Zarubin et al. proposed a furan-rich structure with ether and (hemi) acetal linkages (elemental analyses, IR, NMR of acetone extracts). ${ }^{33}$ Lund et al. reported that humins from HMF are formed by aldol condensation reactions of the intermediate 2,5-dioxo-6-hydroxyhexanal (including reactions with HMF) giving a furan rich structure, with the exact amounts of furanic fragments depending on the level of HMF involved in the aldol condensation reactions. ${ }^{34}$ 
We have recently reported on the structure of so called artificial humins, which are humins made by the conversion of C6sugars, particularly glucose, at elevated temperatures in water in the presence of a mineral acid at extended reaction times ( $6 \mathrm{~h}, 180{ }^{\circ} \mathrm{C}, 1 \mathrm{M}$ sugar and $0.01 \mathrm{M} \mathrm{H}_{2} \mathrm{SO}_{4}$ ). The glucose humins were obtained in yields up to $39 \mathrm{wt} \%$ on C6 sugar intake. ${ }^{27}$ Based on extensive characterisation studies (elemental analysis, IR, solid state NMR and pyrolysis GC-MS) a structural model was proposed, which suggest that the humins consist of furanic fragments connected by various linkages (Fig. 1 left). A later study came up with a refined model, see Fig. 1 right. ${ }^{27,35}$

A number of investigations have been reported to convert the solid humins to higher added value products. For instance, Hoang et al. studied the valorisation of humins by steam reforming with alkali-metal-based catalysts $\left(900-1200{ }^{\circ} \mathrm{C}\right) \cdot .^{36,37}$ Highest activity was found when using $\mathrm{Na}_{2} \mathrm{CO}_{3}$ as the catalyst. The $\mathrm{H}_{2}$ to $\mathrm{CO}$ ratio of the produced syngas was about 2 . However, substantial loss of carbon was observed during the heating up stage (up to $45 \mathrm{wt} \%$ on intake).

Liquefaction of humins has also been proposed as an attractive technology to obtain liquid energy carriers preferably enriched in interesting biobased building blocks like aromatics and alkylphenolics. Such liquefied humins have a higher energy density per volume, and are more easy to store and transport than the solid humins. Liquefaction using pyrolysis technology was investigated by Rasrendra et al. ${ }^{38}$ Pyrolysis GC-MS showed the presence of furanics and organic acids in the vapour phase, though the individual components were present in only minor amounts $(<1 \mathrm{wt} \%)$. Micro-pyrolysis yielded $30 \mathrm{wt} \%$ gaseous and liquid products, the remainder being a solid char. Gas-liquid yields were lower than obtained for a typical lignin sample (Kraft lignin) under similar conditions. As such, pyrolysis seems to be cumbersome leading to relatively low liquid yields.

Recently, Trautmann et al. have reported studies on the conversion of HTC materials to biofuels using catalytic technology. ${ }^{39,40}$ Various HTC materials were tested using Ni on titania as the catalyst at temperatures between 200 and $250{ }^{\circ} \mathrm{C}$, and reaction times between 3 and $20 \mathrm{~h}$. Hydrogen is formed in situ which then serves as the reactant for hydrocracking reactions and the formation of liquid products. Although HTC materials derived from lignocellulosic biomass are likely more complex in nature than the artificial humins from C6-sugars, it implies that this methodology may also be very attractive for the liquefaction/upgrading of artificial humins.

The catalytic liquefaction of humin substances extracted from biodegraded lignocellulosic biomass has also been reported. ${ }^{41}$ The reaction was carried out using RANEY® ${ }^{\circledR i}$ as the catalyst, at $380{ }^{\circ} \mathrm{C}$ using tetralin as the hydrogen donor. Although the structure of the humin (fractions) used in this study differs considerably from those used in our study (hydrothermal synthesis of glucose), its shows that catalytic hydrotreatments without external molecular hydrogen are possible.

We have recently reported that artificial humins derived from glucose can be depolymerised using a hydrotreatment with $\mathrm{Ru} / \mathrm{C}$ in an isopropanol/formic acid mixture. The reaction was carried out at $400{ }^{\circ} \mathrm{C}$ and humin conversions up to $69 \%$ were achieved. ${ }^{42}$ The liquid products were shown to consist of both mono- and oligomeric compounds, and the major GC detectables compounds were alkylphenolics, aromatics (mono and with multiple fused rings) and cyclic alkanes, though their yields based on humin intake is relatively low $(<10 \%)$. It was shown that molecular hydrogen is formed in situ by the catalytic conversion of formic acid and that this in situ produced hydrogen is used for hydrogenolysis and hydro(deoxygenation) reactions involving the humin structure. In addition IPA was also shown to be reactive under these conditions and was (partly) converted to acetone and hydrogen. The later finding indicates that formic acid is possibly not required for the liquefaction reaction and this would considerably simplify the process.

Herein, we report a systematic catalyst screening study on the liquefaction of humins in IPA only, without the use of formic acid and the addition of molecular hydrogen. A series of noble metals including Pd, Ru, Rh, Pt were selected and tested for the reaction with active carbon as the support. The metals

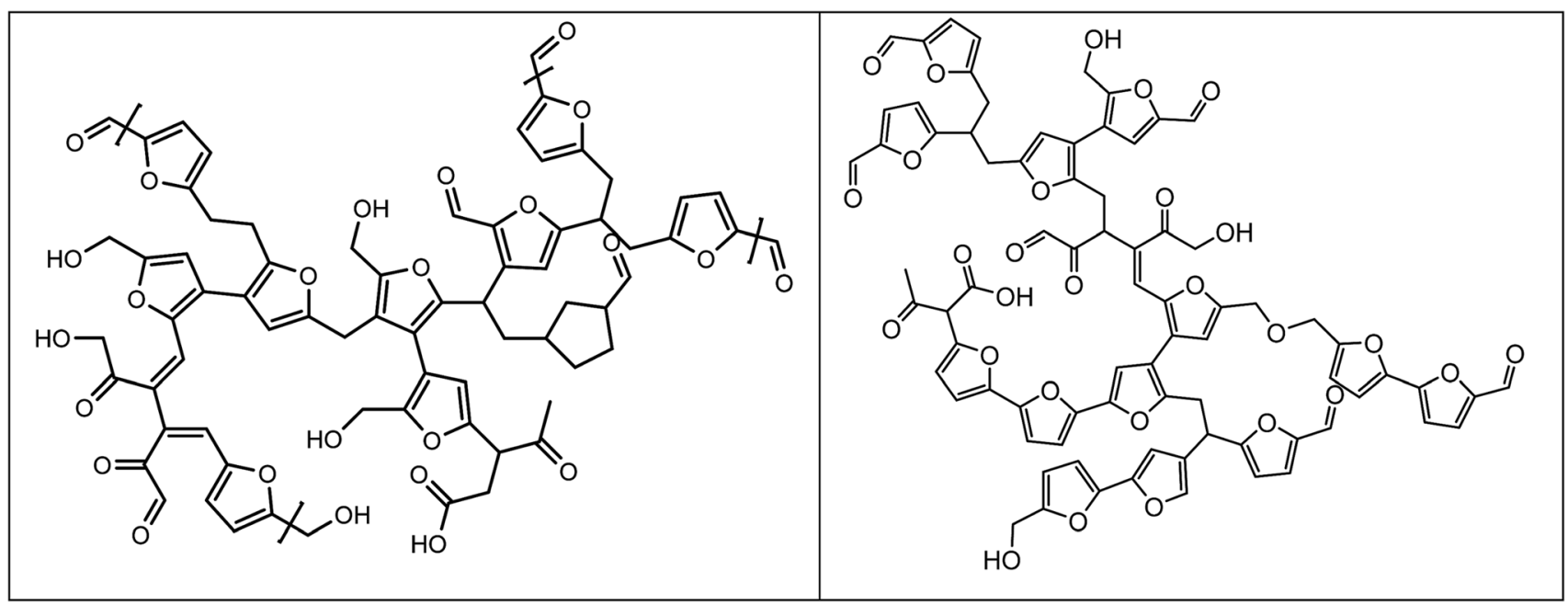

Fig. 1 Proposed structures for humins from D-glucose (reproduced with permission). ${ }^{27,35}$ 
were selected on the basis of their known activity for the dehydrogenation of IPA to hydrogen and acetone. On the basis of this study, the best noble metal was selected, followed by a support screening study (carbon, $\mathrm{TiO}_{2}, \mathrm{ZrO}_{2}$ and $\mathrm{CeO}_{2}$ ). The liquid product phases of the reactions were investigated in detail with various techniques (GPC, GCxGC, GC-MS-FID) to determine the molecular composition. This information was used to select the best catalyst with regards to humin conversion and amounts of low molecular weight products in the product oils.

\section{Materials and methods}

\subsection{Chemicals}

All chemicals used in this work were of analytical purity and used without further purification. The metal acetylacetonate precursor, Pt(acetylacetonate) $)_{2}$ was obtained from Sigma Aldrich with a purity of at least $99.5 \mathrm{wt} \%$. The supports (anatase $\mathrm{TiO}_{2}$, Sigma No. 637254-50G, $\mathrm{ZrO}_{2}$, Sigma No. 230693-100G, and $\mathrm{CeO}_{2}$, Sigma No. 544841-25G) were obtained from Sigma Aldrich and all have an average particle size diameter of less than $50 \mathrm{~nm}$. Supported metal catalysts on carbon (Ru, Sigma No. 206180-25G, Rh, Sigma No. 643149-10G, Pt, Sigma No. 205931-50G, Pd, Sigma No. 205680-50G, all in powder form) with a metal loading of 5 wt $\%$ were obtained from Sigma Aldrich and used as such. 2Propanol (99.5\%, Chromasolv plus) was purchased from Fluka, D-glucose (99\% purity), di- $n$-butylether (DBE), tetrahydrofuran (THF) and sulfuric acid were obtained from Sigma Aldrich. Nitrogen gas (>99.8\%) was obtained from Hoekloos.

\subsection{Humin synthesis}

The humins used in this study were synthesised by the hydrothermal conversion of D-glucose in water in the presence of sulfuric acid according to a literature procedure. ${ }^{27}$

A stainless steel autoclave $(1 \mathrm{~L})$ equipped with an overhead stirrer was filled with a solution of $\mathrm{H}_{2} \mathrm{SO}_{4}(0.01 \mathrm{M})$ and glucose $(1$ $\mathrm{M})$ in water $(500 \mathrm{~mL})$. The content was heated to $180{ }^{\circ} \mathrm{C}$ (heating rate: $1.3{ }^{\circ} \mathrm{C} \min ^{-1}$ ) and subsequently maintained at this temperature for $6 \mathrm{~h}$ at a stirring rate of $120 \mathrm{rpm}$. The initial pressure was 10 bar, which increased slowly during the reaction to 13.5 bar due to the formation of some gasphase components. After reaction, the reactor was cooled to room temperature and the resulting suspension was filtered. The dark brown residue was washed with $3 \mathrm{~L}$ of deionised water. The powder was dried under vacuum ( $0.03 \mathrm{bar})$ for $24 \mathrm{~h}$ at $60^{\circ} \mathrm{C}$. After drying, the humins were grinded and purified by a Soxhlet extraction with water for $24 \mathrm{~h}$. Finally, the purified humins were vacuum ( 0.03 bar) dried for $24 \mathrm{~h}$ at $70{ }^{\circ} \mathrm{C}$ and were further crushed into powder. The elemental composition of the humins was $64.64 \mathrm{wt} \%$ carbon, $4.38 \mathrm{wt} \%$ hydrogen and $30.9 \mathrm{wt} \%$ oxygen by difference $(\mathrm{H} / \mathrm{C}: 0.81$ and $\mathrm{O} / \mathrm{C}$ : $0.36 \mathrm{~mol} \mathrm{~mol}^{-1}$ ), which agrees well with reported values. ${ }^{27}$

\subsection{Catalyst preparation}

All Pt catalysts on the inorganic supports (5 wt\% metal) were prepared using a wet impregnation procedure with acetone as the solvent. The supports were dried overnight at $120^{\circ} \mathrm{C}$ before use. A representative example for $\mathrm{Pt}$ on $\mathrm{TiO}_{2}$ is given as an example. Platinum acetylacetonate $(0.1063 \mathrm{~g}, 0.0527 \mathrm{~g} \mathrm{Pt})$ was diluted in acetone $(250 \mathrm{~mL})$ and the appropriate amount of $\mathrm{TiO}_{2}$ $(1.0235 \mathrm{~g}$ ) was added. The acetone was slowly removed (about 8 h) while heating the suspension at $40{ }^{\circ} \mathrm{C}$ at atmospheric pressure. The resulting solid mixture was collected and calcined in a muffle furnace under air (heating profile: from room temperature to $300{ }^{\circ} \mathrm{C}$ with a heating rate of $5{ }^{\circ} \mathrm{C} \min ^{-1}$ for $2 \mathrm{~h}$ followed by heating to $600{ }^{\circ} \mathrm{C}$ with a rate of $5{ }^{\circ} \mathrm{C} \mathrm{min}{ }^{-1}$ for $1 \mathrm{~h}$ followed by cooling to $50{ }^{\circ} \mathrm{C}$ in $3 \mathrm{~h}$ ). Subsequently, the catalyst was reduced (room temperature to $600{ }^{\circ} \mathrm{C}$ with a heating rate of

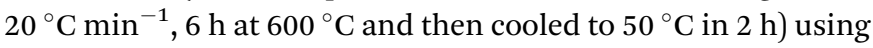
a Micrometrics AutoChem II 2920 system with a sweep gas consisting of $10 \mathrm{vol} \%$ hydrogen and $90 \mathrm{vol} \%$ nitrogen.

\subsection{Catalytic liquefaction of the humins}

The catalytic hydrotreatment experiments were performed in a batch Parr reactor system (maximum operating conditions: 350 bar and $500{ }^{\circ} \mathrm{C}$ ) consisting of a batch autoclave $(100 \mathrm{~mL})$ with electric heating, equipped with an overhead stirrer and temperature control. The stirring speed was set at $1400 \mathrm{rpm}$ for all experiments. In a typical experiment, the reactor was charged with a humin sample ( $3.0 \mathrm{~g})$, IPA (20.0 g), and metal on carbon catalyst $(0.5 \mathrm{~g}, 17 \mathrm{wt} \%$ on humin intake). The reactor was closed and tested for leakage by pressurising with 80 bar of nitrogen. The pressure was released and the reactor was subsequently flushed twice with nitrogen gas. The reactor was weighted for mass balance calculations and subsequently heated to $400{ }^{\circ} \mathrm{C}$ at a rate of about $10{ }^{\circ} \mathrm{C} \mathrm{min}^{-1}$ and the reaction was allowed to proceed for $3 \mathrm{~h}$. During heating, the pressure in the reactor increased typically to 120-130 bar when the temperature approached $400{ }^{\circ} \mathrm{C}$. After reaction, the reactor was cooled to room temperature. The pressure was released and the gas phase was collected in a $3 \mathrm{~L}$ plastic gas bag and was analysed with gas chromatography. The reactor was weighed and the difference in weight before and after reaction (after release of the gasphase) was taken as the amount of gasphase components formed. The suspension was removed from the reactor, weighed and placed in a centrifuge tube $(50 \mathrm{~mL})$. After $45 \mathrm{~min}$ of centrifugation at $4500 \mathrm{rpm}$, a clear liquid phase and a solid phase were obtained. The liquid phase was separated and weighed. The solid residue (unreacted humins and catalyst) was dried at $70{ }^{\circ} \mathrm{C}, 0.03 \mathrm{bar}$ overnight and weighted for mass balance calculations. An overview of the catalytic liquefaction protocol is shown in Fig. 2.

The conversion of humins was calculated as follows:

Humin conversion $=$

$$
\frac{\text { humin, in - (solids, out - intake catalyst })}{\text { humin, in }} 100 \%
$$

The humin oil yield on humin intake (eqn (2)), humin oil on total feed intake (eqn (3)) are mass based and are calculated as follows:

Humin oil yield on humin intake $=\frac{\text { weight of humin oil }}{\text { humin intake }} 100 \%$ 


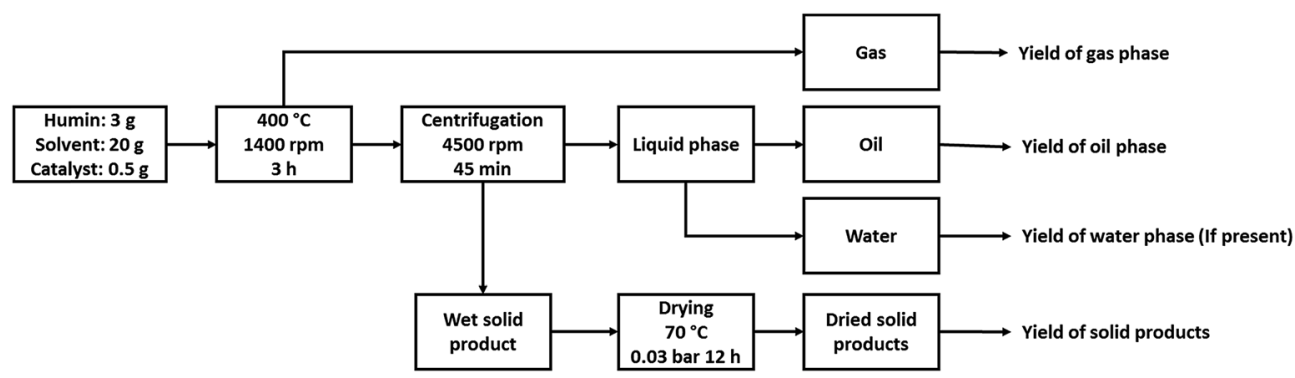

Fig. 2 Experimental protocol for the catalytic liquefaction of humins in 2-propanol.

Humin oil yield on total feed intake

$$
=\frac{\text { weight of humin oil }}{\text { total feed intake }} 100 \%
$$

here the feed intake is the sum of the IPA and humin intake.

\subsection{Product analysis}

2.5.1 GC-MS/FID. GC-MS-FID analyses were performed on organic product samples using a Hewlett Packard 5890 series II plus equipped with a Quadrupole Hewlett Packard 5972 MSD and an FID. A Restek RTX-1701 capillary column $(60 \times 0.25 \mathrm{~mm}$ i.d. and $0.25 \mu \mathrm{m}$ film thickness) was used which was split in a $1: 1$ ratio to the MSD and FID. The injector temperature was set at $250{ }^{\circ} \mathrm{C}$. The oven temperature was kept at $40{ }^{\circ} \mathrm{C}$ for $5 \mathrm{~min}$ and then heated up to $250{ }^{\circ} \mathrm{C}$ at a rate of $3{ }^{\circ} \mathrm{C} \mathrm{min}^{-1}$.

2.5.2 Two-dimensional gas chromatography (GCxGC). GCxGC analyses were performed on a Trace 2D-GC system from Interscience equipped with a cryogenic trap and two columns $(30 \mathrm{~m} \times 0.25 \mathrm{~mm}$-i.d. and $0.25 \mu \mathrm{m}$-film sol-gel capillary column connected to a $148 \mathrm{~cm} \times 0.1 \mathrm{~mm}$-i.d. and $0.1 \mu \mathrm{m}$-film Restek 1701 column). A flame ionisation detector (FID) was used. A dual-jet modulator was applied using carbon dioxide to trap the samples. Helium was used as the carrier gas (flow rate of $0.6 \mathrm{~mL}$ $\min ^{-1}$ ). The injector temperature and FID temperature were set at $250{ }^{\circ} \mathrm{C}$. The oven temperature was kept at $40^{\circ} \mathrm{C}$ for $5 \mathrm{~min}$ and then heated to $250{ }^{\circ} \mathrm{C}$ with a rate of $3{ }^{\circ} \mathrm{C} \mathrm{min}{ }^{-1}$. The pressure was set at 0.7 bar. The modulation time was $6 \mathrm{~s}$.

From the 2D-GC spectra, the yields of aromatics, phenolics, ketones, alkanes, naphthenes and acid were calculated based on the humin intake. The identification of main GCxGC component groups (e.g. alkanes, aromatics, alkylphenolics) in the lignin oils was done by spiking with representative model compounds for the component groups. Quantification was performed by using an average relative response factor (RRF) per component group with di- $n$-butyl ether (DBE) as the internal standard. Details of the procedure are given in ref. 43.

2.5.3 Gas phase analyses. The gas phase samples were collected in a gasbag (SKC Tedlar $3 \mathrm{~L}$ sample bag $9.5^{\prime \prime} \times 10^{\prime \prime}$ with a polypropylene septum fitting) after the hydrotreatment reaction. The gaseous products were analysed using a GC (Hewlett Packard 5890 Series II equipped with a Poraplot $\mathrm{Q} \mathrm{Al}_{2} \mathrm{O}_{3} / \mathrm{Na}_{2} \mathrm{SO}_{4}$ column and a molecular sieve (5 ̊) column) and a thermal conductivity detector (TCD). Both columns were maintained at the same temperature. The injector and detector temperature were set at $150{ }^{\circ} \mathrm{C}$ and $90{ }^{\circ} \mathrm{C}$ respectively. The oven temperature was kept at $40^{\circ} \mathrm{C}$ for $2 \mathrm{~min}$ and then heated to $90^{\circ} \mathrm{C}$ at a rate of $20^{\circ} \mathrm{C} \mathrm{min}{ }^{-1}$ and kept at this temperature for another $2 \mathrm{~min}$. For identification and quantification, a reference gas mixture (55.19\% $\mathrm{H}_{2}, 19.70 \% \mathrm{CH}_{4}, 3.00 \% \mathrm{CO}, 18.10 \% \mathrm{CO}_{2}, 0.51 \%$ ethylene, $1.49 \%$ ethane, $0.51 \%$ propylene and $1.50 \%$ propane) was used.

2.5.4 Elemental analysis. Elemental analysis (C, H, N) of the product oils were carried out using an automated Euro Vector EA3000 CHNS analyser with acetanilide as a calibration reference. The oxygen content was determined by the difference of CHN. All the samples were analysed twice and the average values are reported in this study.

2.5.5 GPC analyses. GPC analyses of the product oils were performed on a HP1100 from Hewlett Packard equipped with three MIXED-E columns $(300 \times 7.5 \mathrm{~mm}$, PLgel $3 \mu \mathrm{m})$ in series and a GBC LC 1240 RI detector. The average molecular weights were determined using the PSS WinGPC Unity software from Polymer Standards Service. The following operating conditions

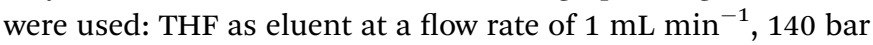
pressure, a column temperature of $42{ }^{\circ} \mathrm{C}$, an injection volume of $20 \mu \mathrm{L}$ with sample concentrations of $10 \mathrm{mg} \mathrm{mL}^{-1}$. Toluene was used as a flow marker and polystyrene samples with different molecular weights were used as the calibration standards.

\subsection{Catalyst characterisation}

Transmission electronic microscopy (TEM) images were obtained using a Philips CM12 operated at an acceleration voltage of $120 \mathrm{kV}$. Samples for TEM measurements were ultrasonically dispersed in ethanol and subsequently deposited on a mica grid coated with carbon.

ICP analyses were performed on a Perkin Elmer 4300 DV. Solid samples were calcined at $900{ }^{\circ} \mathrm{C}$ and subsequently dissolved in a $2 \%$ wt $\mathrm{HNO}_{3}$ solution. Liquid samples were only dissolved in a $2 \% \mathrm{wt} \mathrm{HNO}_{3}$ solution before analysis.

\section{Results and discussion}

\subsection{Catalyst characterisation for the metal on carbon catalysts}

All noble metal (Pt, Pd, Rh, Ru) on carbon catalysts were obtained from a commercial supplier and contained $5 \mathrm{wt} \%$ of active metal. The average metal nanoparticle size was determined using TEM and two representative images are given in 
Fig. 3. The average metal particle size was below $5 \mathrm{~nm}$ for all samples $3.4 \mathrm{~nm}$ for $\mathrm{Pd} / \mathrm{C}, 2.3 \mathrm{~nm}$ for Pt/C, $4.1 \mathrm{~nm}$ for $\mathrm{Rh} / \mathrm{C}$ and $2.2 \mathrm{~nm}$ for $\mathrm{Ru} / \mathrm{C}$. The $\mathrm{Pd}$ and $\mathrm{Rh}$ sample showed also some evidence for agglomeration of metal nanoparticles, see Fig. 3 (right) and Fig. S1 (ESI†).

\subsection{Exploratory catalyst screening studies for noble metals on a carbon support}

Exploratory catalyst screening studies on humin liquefaction were carried out in IPA using the carbon supported noble metal catalysts. All reactions were performed at $400{ }^{\circ} \mathrm{C}$ for a batch time of $3 \mathrm{~h}$. These conditions were selected on the basis of earlier experiments with $\mathrm{Ru} / \mathrm{C}$ and formic acid/IPA. ${ }^{\mathbf{4 2}}$ An overview of the experiments is given in Table 1 .

3.2.1 Product phases. The amounts of the various product phases is given in Table 1. After the catalytic liquefaction reaction, a single liquid product was obtained in yields ranging between 54 and $80 \%$ yield. Some remaining solid was isolated, which was a mixture of the catalyst and unconverted humins/ humin derived solids (3.1-8 wt\% on intake). Significant amounts of gasphase products were formed, arising mainly from the solvent (IPA, vide infra). This was particularly evident from the pressure built up during heating the reactor to $400{ }^{\circ} \mathrm{C}$, which could be as high as 180 bar.

The gas to liquid phase ratio is about constant for $\mathrm{Pt}, \mathrm{Pd}, \mathrm{Rh}$, whereas $\mathrm{Ru} / \mathrm{C}$ is a clear exception and considerably more gas

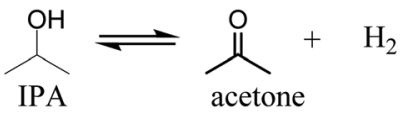

Scheme 1 IPA dehydrogenation to acetone and hydrogen.

phase components are formed. The major gasphase component is hydrogen (qualitatively, not quantified in detail), likely formed by IPA dehydrogenation to acetone and hydrogen (Scheme 1), which is a well precedented equilibrium reaction. ${ }^{\mathbf{4 4 , 4 5}}$

Based on the amount of gasphase components formed during reaction, $\mathrm{Ru}$ is more effective for this IPA dehydrogenation reaction than the other metals under the prevailing reaction conditions. These findings are in line with a kinetic study by Ukisu et al. on the dehydrogenation of IPA with carbon supported catalysts (Ru, Pd, Pt, Rh) at $82{ }^{\circ} \mathrm{C}$ and atmospheric pressure in a batch set-up where the amount of hydrogen formed was measured using a gas-burette. ${ }^{46}$ The order of catalyst activity for IPA dehydrogenation was $\mathrm{Ru} / \mathrm{C}>\mathrm{Rh} / \mathrm{C}=\mathrm{Pt} / \mathrm{C}>$ $\mathrm{Pd} / \mathrm{C}$, with the TOF for $\mathrm{Ru} / \mathrm{C}$ about 5 times higher than for the second best catalysts $(\mathrm{Rh} / \mathrm{C}$ and $\mathrm{Pt} / \mathrm{C})$. Though the reaction temperature in this study is by far lower than in our system (82 versus $400{ }^{\circ} \mathrm{C}$ ), our observation that $\mathrm{Ru}$ is more active for IPA dehydrogenation is in line with these literature data and explains the high amounts of gasphase components formed when using $\mathrm{Ru} / \mathrm{C}$.

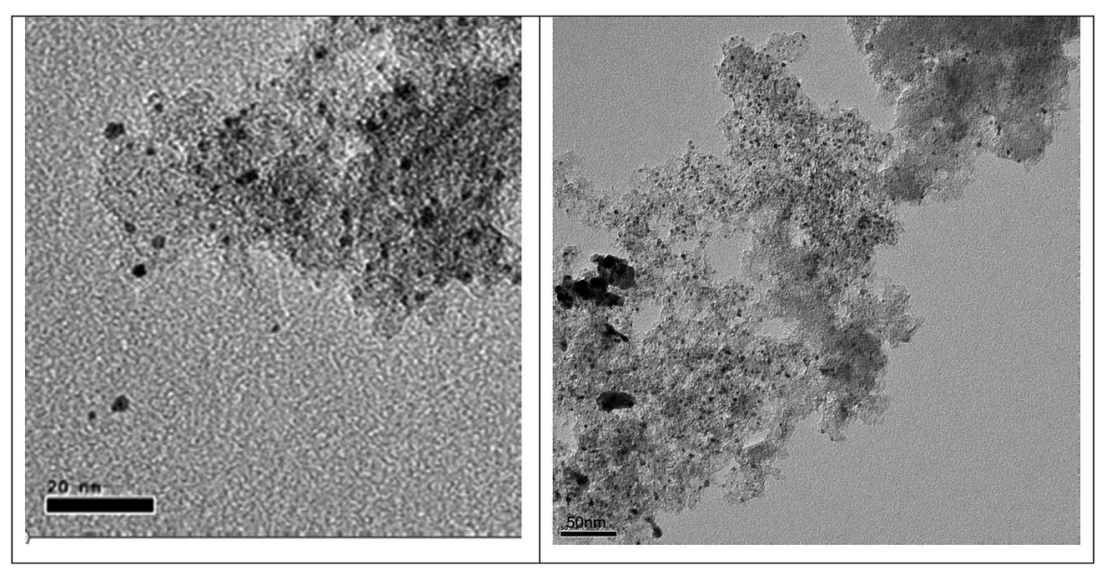

Fig. 3 Representative TEM images for Pt/C (left) and Pd/C (right).

Table 1 Product yields for the catalytic liquefaction of humins using noble metal catalysts on a carbon support ${ }^{a}$

\begin{tabular}{|c|c|c|c|c|c|}
\hline Experiment & 1 & 2 & 3 & 4 & 5 (blank) \\
\hline Catalyst & $\mathrm{Ru} / \mathrm{C}$ & $\mathrm{Rh} / \mathrm{C}$ & $\mathrm{Pd} / \mathrm{C}$ & $\mathrm{Pt} / \mathrm{C}$ & $\mathrm{Pt} / \mathrm{C}$ \\
\hline Humin intake (wt\% on feed) & 13 & 13 & 13 & 13 & - \\
\hline Product oil yield, wt\% on total feed & 54 & 76 & 73 & 78 & 80 \\
\hline Solids, wt\% on total feed & 4.9 & 5.1 & 8.0 & 3.1 & 0 \\
\hline Humin conversion, wt $\%$ & 63 & 61 & 39 & 77 & - \\
\hline Gas phase, wt $\%$ on total feed ${ }^{b}$ & $36^{b}$ & 13 & 14 & 15 & 16 \\
\hline Mass balance closure (\%) & 95 & 94 & 95 & 96 & 96 \\
\hline
\end{tabular}

${ }^{a}$ All reactions were carried out with $13 \mathrm{wt} \%$ humins (from D-glucose) on total intake and $17 \mathrm{wt} \%$ catalyst on humin intake at $400{ }^{\circ} \mathrm{C}$ for $3 \mathrm{~h}$.

${ }^{b}$ Calculated by the difference of weight of the reactor (with liquid and solid material) before and after reaction (after purging the gas phase). 
3.2.2 Humin conversion. The humin conversion was calculated based on the amounts of solids remaining after reaction (eqn (3)) and varied between 39 and $77 \%$. The conversion is a clear function of the catalyst and best results were obtained with $\mathrm{Pt} / \mathrm{C}$, wheras $\mathrm{Pd} / \mathrm{C}$ showed the lowest performance (Table 1). Thus, we can conclude that humins can indeed be depolymerised in yields of up to $80 \%$ when using $\mathrm{Pt} / \mathrm{C}$ in combination with IPA as the hydrogen donor.

3.2.3 Blank reactions. To study the involvement of IPA in the reaction, a blank reaction was performed with IPA only in the absence of humins using the best catalyst in the series (Pt/C) and the results are given in the Table 1 . After reaction, a single liquid phase and considerably amounts of gas phase components were formed. Clearly, IPA is not inert under the given conditions and is partly converted to gasphase components (16 wt $\%$ on feed). Gas phase analysis shows the presence of significant amounts of hydrogen (up to $90 \mathrm{~mol} \%$ ), indicative for the occurrence of IPA dehydrogenation to acetone and hydrogen (Scheme 1). This reaction is well known to be catalysed by $\mathrm{Pt} / \mathrm{C}$ and is actually desired to provide in situ hydrogen for the depolymerisation/ hydrodeoxygenation reactions of the humins.

3.2.4 Liquid phase composition. The liquid phase after reaction was analysed by GC-MS/FID, GCxCD-FID and GPC to (i) determine the chemical composition, (ii) gain insights in the molecular transformation during reactions of both the humins and IPA and (iii) probe possible catalyst effects on the product composition.

3.2.5 GC-MS-FID. GC-MS-FID analyses for the samples showed, particularly for $\mathrm{Pt} / \mathrm{C}$ and $\mathrm{Ru} / \mathrm{C}$, the presence of a wide range of individual products, see Fig. 4 and 5 for details.
For Rh and Pd, the amounts of GC detectable species at the same GC magnification level was by far lower (Fig. S2 and S3 in the ESI $\dagger$ ). This was also confirmed by GCxGC measurements (vide infra). As such, significant amounts of higher molecular weight, non GC-detectable species are expected to be present in the liquid product phase, particularly for Rh and Pd. This was indeed shown by GPC measurements of the product oils. A representative example for $\mathrm{Pd} / \mathrm{C}$ is shown in Fig. 6 and shows the presence of a higher molecular weight tail, along with peaks corresponding to low molecular weight products (humin derived monomers and IPA and reaction products derived thereof).

IPA was still present in all samples (not shown in Fig. 4 and 5 , retention time is below $8 \mathrm{~min}$ ), indicative that IPA conversion by dehydrogenation reactions is far from quantitative at the prevailing reaction conditions. For $\mathrm{Pt} / \mathrm{C}$ major components are methyl-isobutylketone (MIBK, 3), its hydrogenated product (4), and two other 9 carbon aliphatic ketones $(6,7)$. All are likely formed from subsequent aldol condensation reactions of acetone (formed by IPA dehydrogenation to acetone, which was also detected at low retention times), see Scheme 2 for details. ${ }^{47}$ Compound 7 is a known reaction product when reacting MIBK with ethanol using $\mathrm{Pd} / \mathrm{C}$ as the catalyst. ${ }^{48}$

In addition, some phenolics and aromatics/naphtalenes were present, which most likely arise from the depolymerisation/hydro(-deoxy)genation of humins. However, in the case of $\mathrm{Ru} / \mathrm{C}$, a clear peak was present at about $22 \mathrm{~min}$ (compound g, Fig. 5). This peak was assigned to as either 1methyl-4-ethylbenzene or 1,3,5-trimethylbenzene by the MS library. Injection of both pure components show that

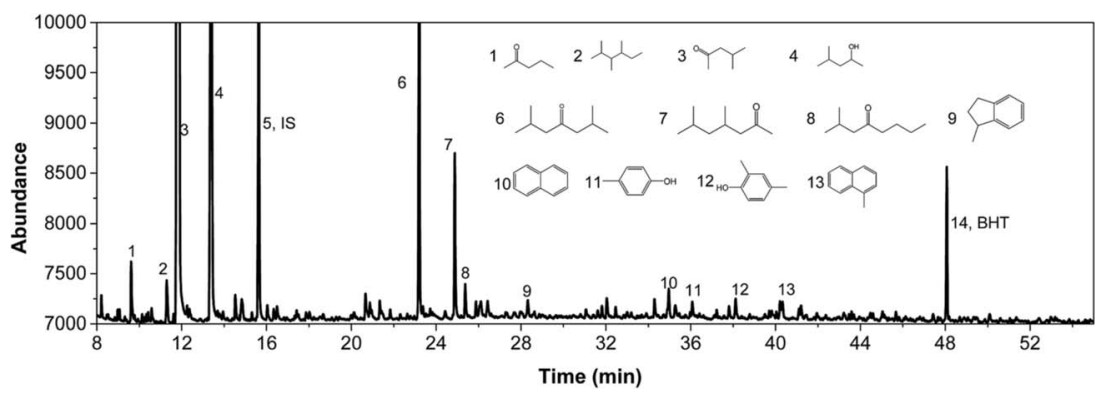

Fig. 4 GC-MS/FID spectrum of the product phase of an experiment with Pt/C $\left(400^{\circ} \mathrm{C}, 3 \mathrm{~h}\right)$. The exact position of substituents on the aromatic ring for 9, 11, 12 and 13 could not be established unequivocally by the GC-MS database.

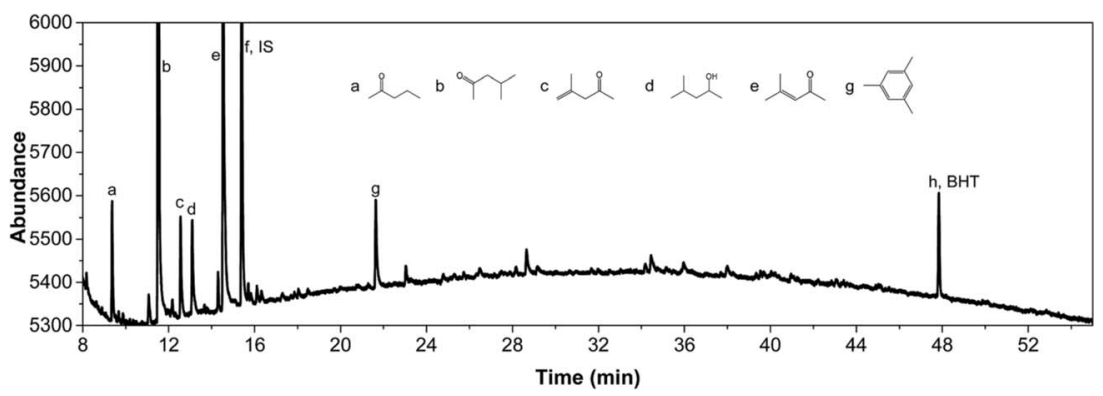

Fig. $5 \mathrm{GC}-\mathrm{MS} / \mathrm{FID}$ spectrum of the product phase of an experiment with $\mathrm{Ru} / \mathrm{C}\left(400{ }^{\circ} \mathrm{C}, 3 \mathrm{~h}\right)$. 


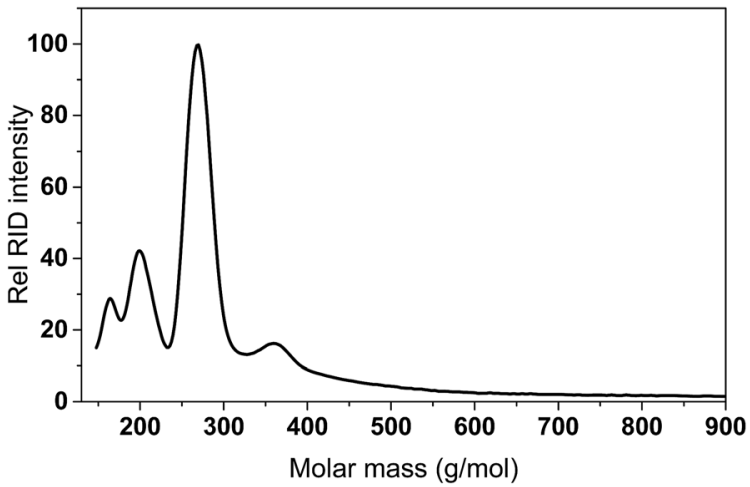

Fig. 6 GPC chromatogram of the product oil for a catalytic hydrotreatment experiment with $\mathrm{Pd} / \mathrm{C}$.

component $\mathrm{g}$ is actually 1,3,5 trimethylbenzene based on retention times. As such, it is likely not derived from humins but a product from the cyclisation reaction of the aldolcondensation product mesityloxide with acetone. ${ }^{49}$ Thus, not all aromatics present in the reaction mixture are by definition derived from the humins. Further quantification of component classes was done by GCxGC and will be discussed in the following.

3.2.6 GCxGC analysis of the products. The composition of the liquid phase was quantified by using GCxGC-FID. A representative example of a chromatogram for $\mathrm{Ru} / \mathrm{C}$ is given in Fig. $\mathrm{S} 4$ (ESI $\dagger$ ). Significant amounts of products belonging to the ketone/alcohol, aromatic, (cyclic) alkanes and alkylphenolic component classes were observed. The total amounts of the peaks in the product groups were quantified and the results are given in Table 2 . Here, the amount of a certain product group is given as the percentage based on total GC detectables by GCxGC. It is evident that by far the most abundant compounds are ketones and alcohols, in line with the GC/MS-FID results. These are formed by subsequent reactions of acetone (Scheme 2). In addition, aromatics and alkylphenolics are also observed. The latter component class is not formed by acetone
Table 2 Overview of the composition of the liquid phase by $\mathrm{GCxGC}^{a}$

\begin{tabular}{lllll}
\hline Catalyst & $\mathrm{Pt} / \mathrm{C}$ & $\mathrm{Pd} / \mathrm{C}$ & $\mathrm{Rh} / \mathrm{C}$ & $\mathrm{Ru} / \mathrm{C}$ \\
Alkylphenolics & 6 & 15 & 31 & 12 \\
Aromatics & 9 & 9 & 8 & 6 \\
$\begin{array}{l}\text { Linear/branched } \\
\text { alkanes }\end{array}$ & $<1$ & $<1$ & $<1$ & $<1$ \\
Cyclic alkanes & & & & \\
Ketones/alcohols $^{b}$ & 3 & 26 & 14 & 4 \\
& 80 & 49 & 44 & 76
\end{tabular}

${ }^{a}$ In wt $\%$ based on GC detectable in the liquid phase; product classes containing only minor amounts of products are not shown (e.g. organic acids). ${ }^{b}$ Excluding acetone and IPA.

condensation reactions and as such, the individual components are most likely derived from the humins by depolymerisation reactions (vide infra).

Further confirmation was obtained by comparing the GCxGC chromatograms (Fig. S5, ESI $\dagger$ ) for the reactions with $\mathrm{Pt} / \mathrm{C}$ in the presence and absence of humins (blank reaction). It is clearly evident that the blank reaction gives considerable amounts of ketones and alcohols arising from IPA, whereas particularly the alkylphenolics are absent. The latter component group is clearly visible when using humins, indeed a strong indication that the alkylphenolics are derived from the humins. The blank reactions show only one clear peak in the aromatics region, which was identified as 1,3,5-trimethyl-benzene, a known product from condensation reactions between mesityloxide and acetone (Scheme 2). ${ }^{50-53}$ As such, at least one of the aromatic components in the product mixture is derived from IPA/acetone and not solely from the humins.

The relative amounts of alkylphenolics in the GC detecables is the highest for $\mathrm{Rh} / \mathrm{C}$, whereas about similar amounts of aromatics were found for all catalysts (Table 2). The amounts of ketones/alcohols was highest for $\mathrm{Pt} / \mathrm{C}$ and $\mathrm{Ru} / \mathrm{C}$, and by far lower for $\mathrm{Pd} / \mathrm{C}$, in line with a lower acetone dehydrogenation activity of the latter. However, of interest is also the amounts of GC detectables on humin intake. Though difficult to determine accurately by GCxGC due to the presence of the large amounts

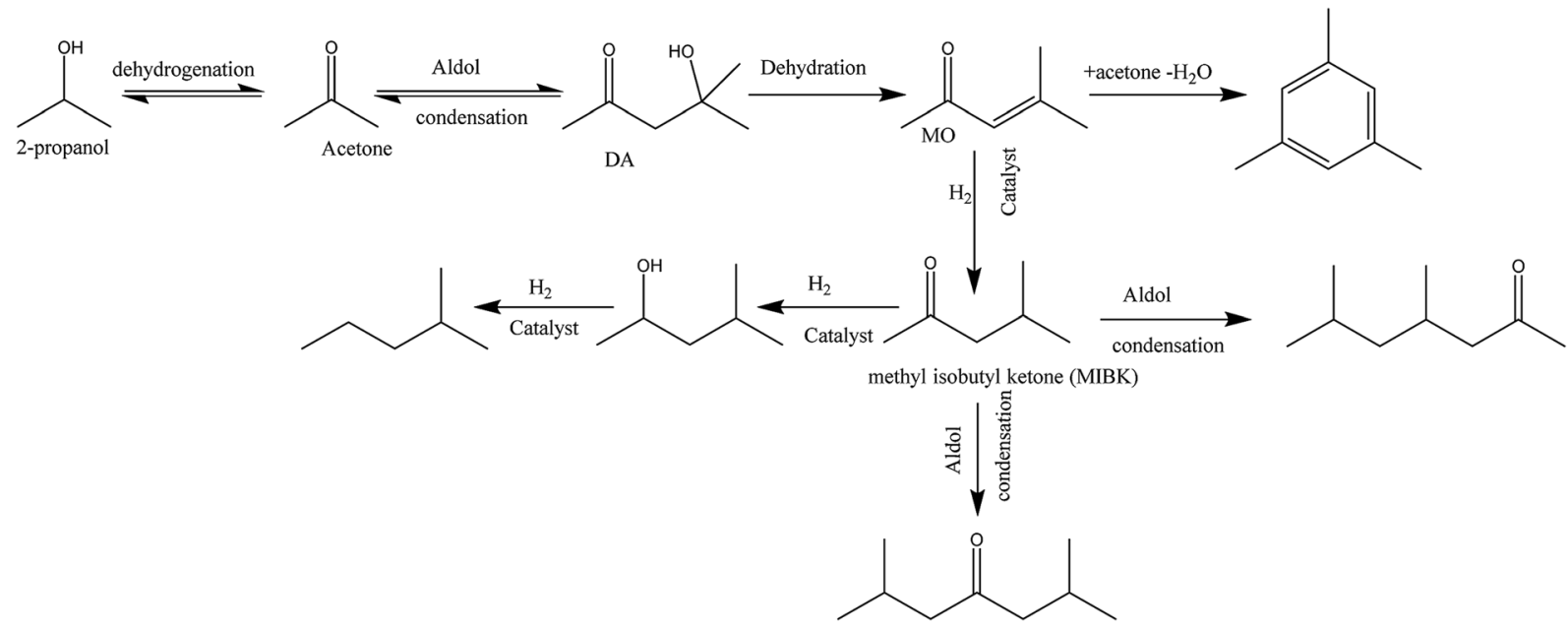

Scheme 2 Possible reaction pathway for IPA. 
of individual components, a semi-quantitative assessment is possible when using average relative response factors for the various component classes. ${ }^{43}$ The results are given in Table 3.

The amounts of GC detectables on humin intake is by far highest for Pt/C (about 53\%), followed by $\mathrm{Ru} / \mathrm{C}(25 \%)$, whereas the amounts are very low $(<2 \%)$ for both Pd and $\mathrm{Rh}$. These findings are in line with the peak intensities in the GC-MS chromatograms (Fig. 4, 5, S2 and S3 in the ESI†). It is also evident that the main GC detectables are derived from IPA, in amounts varying from 1-43 wt $\%$ on humin intake. The highest amounts were obtained for $\mathrm{Pt} / \mathrm{C}$, followed by $\mathrm{Ru} / \mathrm{C}$. When considering the dehydrogenation activity of IPA for the various catalyst, highest amounts of IPA/acetone derived products are expected for $\mathrm{Ru} / \mathrm{C}$, which shows higher dehydrogenation activity than Pt/C. However, this is not the case, implying that the subsequent aldolcondensation reactions of acetone are more promoted by $\mathrm{Pt} / \mathrm{C}$ than by $\mathrm{Ru} / \mathrm{C}$.

Of interest is the amount of low molecular weight, volatile, GC detectable humin derived products (alkylphenolics and part of the aromatics). These are highest for $\mathrm{Pt} / \mathrm{C}$ ( $9.6 \mathrm{wt} \%$ on humin intake), followed by $\mathrm{Ru} / \mathrm{C}$ ( $5.7 \mathrm{wt} \%$ on humin intake). As such, when aiming for alkylphenolics, humin liquefaction is best performed using Pt/C. The presence of relatively low amounts of GC detectable compounds derived from the humins implies that product oils contain higher molecular weight, non-GC detectable compounds, in line with the higher molecular weight tail as observed by GPC (Fig. 6).

\subsection{Reaction pathways}

We have recently proposed a reaction network for the catalytic depolymerisation of humins using $\mathrm{Ru} / \mathrm{C}$ in combination with formic acid and IPA. ${ }^{42}$ This network, excluding chemistry from formic acid, appears also valid for the metal catalysed reactions in IPA only (Fig. S6, ESI†े). It consists of a number of parallel/ consecutive reactions. The first step in the sequence is the depolymerisation of the humin structure to lower molecular weight fragments. This reaction may be thermally induced, as was shown recently by pyrolysis experiments with various humin sources. ${ }^{53}$ However, it is also likely that the metal

Table 3 Overview of the composition of the liquid phase based on humin intake ${ }^{a}$

\begin{tabular}{lcccc}
\hline Catalyst & $\mathrm{Pt} / \mathrm{C}$ & $\mathrm{Pd} / \mathrm{C}$ & $\mathrm{Rh} / \mathrm{C}$ & $\mathrm{Ru} / \mathrm{C}$ \\
\hline Humin derived products (wt\% on humin intake) & & \\
Alkylphenolics & 3.1 & 0.2 & 1.4 & 3.2 \\
Aromatics $^{b}$ & 5.0 & 0.2 & 0.4 & 1.4 \\
(Cyclic) alkanes & 1.5 & 0.5 & 0.6 & 1.1 \\
Total humin derived (wt\%) & 9.6 & 0.9 & 2.4 & 5.7
\end{tabular}

IPA derived products (wt\% on humin intake)

$\begin{array}{lllll}\text { Ketones/alcohols }^{c} & 43 & 0.9 & 2 & 19\end{array}$

${ }^{a}$ In wt $\%$ based on humin intake in the liquid phase; experimental conditions: $400{ }^{\circ} \mathrm{C}, 3 \mathrm{~h} .{ }^{b}$ Includes also 1,3,5-trimethylbenzene, the product from the aldol condensation/cyclisation reactions involving acetone. ${ }^{c}$ Excluding acetone and IPA. catalysts play a role here, e.g. by hydrogenolysis reactions of linkages in the humin structure with molecular hydrogen produced from IPA dehydrogenation. At this stage, it is not clear whether the actual furanic structure of the humins is cleaved to lower molecular weight fragments or that the furanic humin structure is (partly) converted to a more aromatic structure and then depolymerised. This aromatisation of the humin structure has been observed both for gasification experiments with humins $s^{36,37,54}$ as well as for a base catalysed treatment of the humins at about $200-250{ }^{\circ} \mathrm{C} .{ }^{55}$ Further catalytic breakdown of the structures will lead to the formation of alkylphenolics and/ or furanics. Furanics were not observed in the reaction mixture and a possible reaction pathway involves aromatisation of furanics to aromatics, which is a well precedented reaction. ${ }^{56}$ These alkylphenolics may be hydrodeoxygenated to aromatics using supported metal catalysts. In addition, overhydrogenation may occur to give (cyclic) alkanes.

It is of interest to compare the performance of the various catalysts. Evidently, $\mathrm{Pd} / \mathrm{C}$ is by far the worse catalyst, showing the lowest humin conversion and the lowest amounts of GCdetectable components (Table 3). A likely explanation is the low IPA dehydrogenation activity of the $\mathrm{Pd} / \mathrm{C}$ catalyst, in line with literature data, ${ }^{46}$ leading to low amounts of hydrogen in the gasphase. As such, the rate of hydrogenolysis and hydrodeoxygenation reactions is likely very low and humin liquefaction could be mainly due to thermal depolymerisation with the formation of relatively high molecular weight compounds that are not GC detectable. The most active catalyst is $\mathrm{Pt} / \mathrm{C}$, which gives the highest humin conversion and the highest amounts of GC detectable compounds. As such, both the dehydrogenation reaction and the subsequent hydrogenolysis/hydrodeoxygenation reactions are catalysed by Pt/C. On the basis of the known excellent IPA dehydrogenation activity of $\mathrm{Ru} / \mathrm{C}$, leading to considerable amounts of hydrogen which are necessary for the follow up reactions, best performance for this catalyst was anticipated. However, this is not the case and apparently the rate of the subsequent hydrogenolysis and hydrodeoxygenation reactions are slower in the case of $\mathrm{Ru} / \mathrm{C}$ compared to $\mathrm{Pt} / \mathrm{C}$, leading to lower amounts of GC detectable species.

\subsection{Systematic studies for Pt catalysts on various supports}

Best performance regarding humin conversion and the amounts of humin derived low molecular weight alkylphenolics and aromatics was obtained using Pt/C. As such, a subsequent study was performed on support effects for Pt based catalyst. For this purpose, three Pt catalysts on $\mathrm{ZrO}_{2}, \mathrm{TiO}_{2}$ and $\mathrm{CeO}_{2}$ were prepared using a wet impregnation procedure with platinum acetylacetonate as the precursor. After synthesis, the catalysts were calcined $\left(300-600{ }^{\circ} \mathrm{C}\right)$ and reduced $\left(600{ }^{\circ} \mathrm{C}, 10 \%\right.$ hydrogen in nitrogen). For a proper comparison with the carbon based catalyst, the Pt loading on the catalysts was set at $5 \mathrm{wt} \%$.

3.4.1 Catalyst characterisation. The catalysts were analysed by ICP to determine the actual Pt content and by TEM to get insights in the average metal nanoparticle size. The Pt content was between $5.1 \mathrm{wt} \%$ for $\mathrm{Pt} / \mathrm{ZrO}_{2}$ and $4.3 \mathrm{wt} \%$ for $\mathrm{Pt} / \mathrm{CeO}_{2}$, with an intermediate value for $\mathrm{Pt} / \mathrm{TiO}_{2}$ (4.5 wt\%) (Table 4). As such, 
Table 4 Overview of relevant catalyst properties

\begin{tabular}{lll}
\hline Catalyst & ${\text { Pt } \text { content }^{a}(\mathrm{wt} \%)}$ & Average Pt diameter $(\mathrm{nm})$ \\
\hline $\mathrm{Pt} / \mathrm{ZrO}_{2}$ & 5.1 & 8.1 \\
$\mathrm{Pt} / \mathrm{CeO}_{2}$ & 4.3 & Bimodal distribution ${ }^{b}$ about \\
& & $9 \mathrm{~nm}$ for the larger ones \\
$\mathrm{Pt} / \mathrm{TiO}_{2}$ & 4.5 & 8.5 \\
${ }^{a}$ Actual loading as determined by ICP. ${ }^{b}$ See Fig. 7.
\end{tabular}

differences in activity may, among others, also be related to small variations in Pt metal loading.

TEM was used to determine the average Pt nanoparticle sizes and the results are given in Table 4 . The average Pt nanoparticle size for the zirconia and titania supported catalysts are similar and between 8.1-8.5 $\mathrm{nm}$. For the ceria based catalyst, both small and large Pt nanoparticles are observed, see Fig. 7 for details. The average size of the larger Pt particles is about $9 \mathrm{~nm}$, which is close to those in $\mathrm{Pt} / \mathrm{ZrO}_{2}$ and $\mathrm{Pt} / \mathrm{TiO}_{2}$ (Fig. S7 in the ESI $\dagger$ ). The average size of the Pt nanoparticles is relatively large

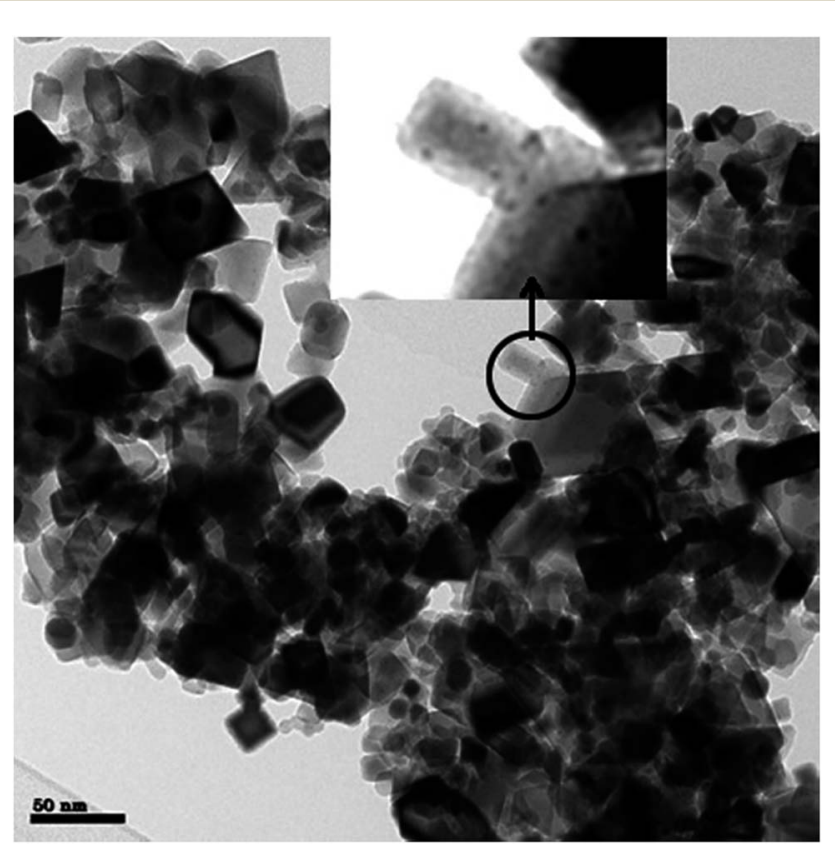

Fig. 7 TEM image of Pt/ceria showing larger and small Pt particles (inset). when comparing literature data for supported Pt catalysts on inorganic supports. ${ }^{57-64}$ Possible explanations are the relatively high metal loading and the use of a rather high reduction temperature (up to $600{ }^{\circ} \mathrm{C}$, see Experimental section), which may lead to sintering/agglomeration during reduction.

3.4.2 Catalyst screening studies for Pt on various inorganic supports. Catalyst screening studies on humin liquefaction were carried out in IPA using the Pt catalysts on various inorganic supports with $\mathrm{Pt} / \mathrm{C}$ as the bench mark. An overview of the experiments is given in Table 5 .

Mass balance closure for all experiments was good and above $93 \%$. The main product was again a single liquid phase, in yields between 62 and $78 \mathrm{wt} \%$ yield. Humin conversion was between 51 and $77 \%$. Highest humin conversion was obtained with $\mathrm{Pt} / \mathrm{C}$, whereas $\mathrm{Pt} / \mathrm{TiO}_{2}$ gave the worse results ( $51 \mathrm{wt} \%$ ). For the latter catalyst, the amount of gas phase components formed is by far the highest and actually about twice as high as for the other catalysts.

\subsection{Analysis of the liquid product phase}

A representative example of a GC-MS chromatogram of the liquid product phase is given in Fig. 8 for $\mathrm{Pt} / \mathrm{TiO}_{2}$, the others are provided in the ESI (Fig. S8 and $\mathrm{S} 9 \dagger$ ). As for $\mathrm{Pt} / \mathrm{C}$, the main reaction products for $\mathrm{Pt} / \mathrm{TiO}_{2}$ are derived from IPA/acetone and include MIBK (4), aldol products with 9 carbon atoms and isophoron (14), hydrogenation products derived thereof $(6,13)$ and 1,3,5-trimethylbenzene (10). Isophoron is only observed in reaction mixtures from $\mathrm{Pt} / \mathrm{TiO}_{2}$, and actually not detected for $\mathrm{Pt} /$ $\mathrm{C}$ (Fig. 4). It is a known condensation product of acetone, which may be formed in the presence of inorganic bases. ${ }^{65-67}$ The observation that isophoron is solely detected when using titania as the support, implies that the support, and likely the acid/ basic properties, plays a role in the formation pathways to isophoron. In addition, peaks particularly from alkylphenolics and aromatics were observed, of which the former certainly arise from the depolymerisation/hydrodeoxygenation of the humin structure and these were further quantified using GCxGC-FID.

The GCxGC-FID spectra for the reaction products for $\mathrm{Pt} / \mathrm{CeO}_{2}$ is given in Fig. 9, those of the others in the ESI (Fig. S10 and $\mathrm{S} 11 \dagger)$. Of interest is the relatively high intensity of the peaks in the alkylphenolics region when using the $\mathrm{Pt} / \mathrm{CeO}_{2}$ catalyst.

The distribution of the various component classes based on GC detectables is given in Table 6 (including $\mathrm{Pt} / \mathrm{C}$ as the bench mark).

Table 5 Product yields for the catalytic liquefaction of humins with Pt catalysts on various inorganic supports ${ }^{a}$

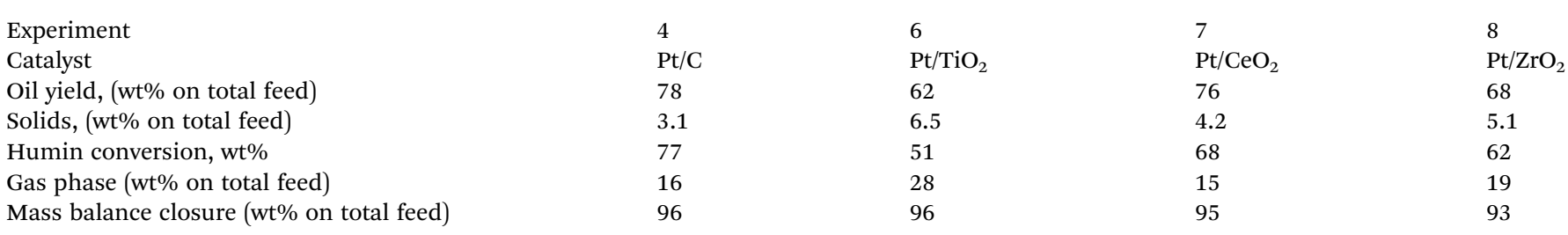

${ }^{a}$ All reactions were carried out with $13 \mathrm{wt} \%$ humins (from D-glucose) on total intake, $17 \mathrm{wt} \%$ catalyst on humin intake and $400{ }^{\circ} \mathrm{C}$ for $3 \mathrm{~h}$. 


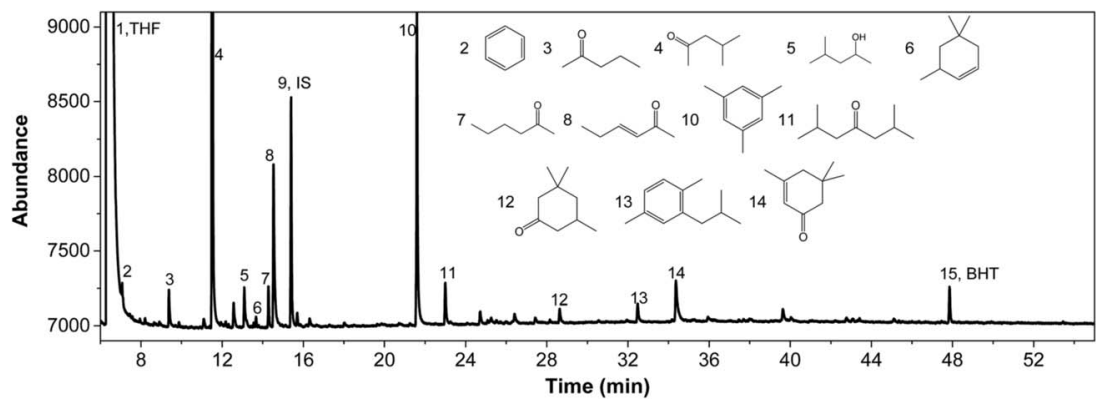

Fig. 8 GC-MS/FID chromatogram of a reaction mixture using $\mathrm{Pt} / \mathrm{TiO}_{2}\left(400{ }^{\circ} \mathrm{C}, 3 \mathrm{~h}\right)$.

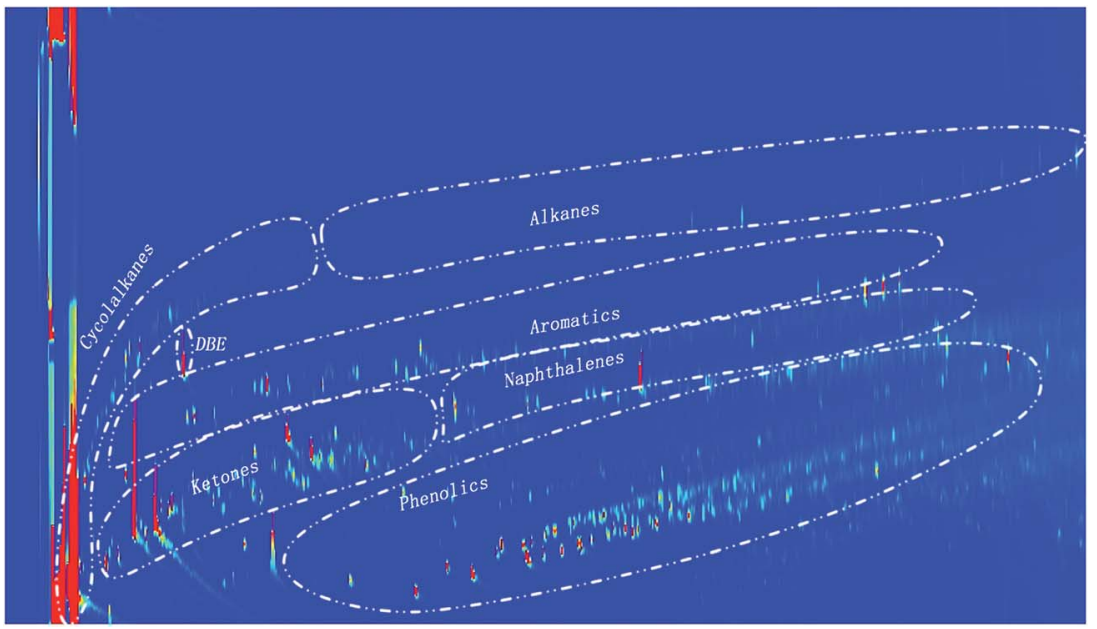

Fig. $9 \mathrm{GCxGC}$ chromatogram for the reaction product using $\mathrm{Pt} / \mathrm{CeO}_{2}\left(400{ }^{\circ} \mathrm{C}, 3 \mathrm{~h}\right)$.

The product distribution for the 4 catalysts differs considerably. Highest amounts of alkylphenolics, products definitely derived from humins and not from IPA/acetone (as proven by blank reactions, vide supra), were found for $\mathrm{Pt} / \mathrm{CeO}_{2}$ (see also Fig. 9). This either suggest that $\mathrm{Pt} / \mathrm{CeO}_{2}$ is a good catalyst for humin depolymerisation/hydro(deoxy)genation reactions to lower molecular weight components or a poor catalyst for the aldolcondensation reactions involving acetone. As such, it is better to compare the amounts of component classes based on humin intake (Table 7).

Table 6 Overview of the composition of the liquid phase on total GC detectables $^{a}$

\begin{tabular}{lllll}
\hline Catalyst & $\mathrm{Pt} / \mathrm{C}$ & $\mathrm{Pt} / \mathrm{TiO}_{2}$ & $\mathrm{Pt} / \mathrm{CeO}_{2}$ & $\mathrm{Pt} / \mathrm{ZrO}_{2}$ \\
Alkylphenolics & 6 & 16 & 30 & 6 \\
$\begin{array}{l}\text { Aromatics } \\
\text { Linear/branched }\end{array}$ & 9 & 11 & 1 & 1 \\
$\begin{array}{l}\text { alkanes } \\
\text { Cyclic alkanes }\end{array}$ & $<0.1$ & $<0.1$ & $<0.1$ & $<0.1$ \\
Ketones/alcohols $^{b}$ & 3 & 4 & 7 & \\
\end{tabular}

${ }^{a}$ Based on GC detectables in the liquid phase by GCxGC-FID; experimental conditions: $400{ }^{\circ} \mathrm{C}, 3 \mathrm{~h}$. Minor component belonging to other product classes are not provided (e.g. organic acids). ${ }^{b}$ Excluding acetone and IPA.
The highest amounts of GC detectables from humins was indeed obtained when using $\mathrm{Pt} / \mathrm{CeO}_{2}$, the majority of the compounds being alkylphenolics. These findings are also in line with the high humin conversion level (68 wt\%, Table 5). Thus we can conclude that particularly $\mathrm{Pt} / \mathrm{CeO}_{2}$ is a good catalyst for the conversion of humins to low molecular weight components and particularly alkylphenolics. When compared to $\mathrm{Pt} / \mathrm{C}$, the humin conversion slightly lower (68 wt\% versus 77 for $\mathrm{Pt} / \mathrm{C}$ ), though the depolymerisation activity is higher for $\mathrm{Pt} /$

Table 7 Overview of the composition of the liquid phase on humin intake (GCxGC-FID) ${ }^{a}$

\begin{tabular}{lccll}
\hline Catalyst & $\mathrm{Pt} / \mathrm{C}$ & $\mathrm{Pt} / \mathrm{TiO}_{2}$ & $\mathrm{Pt} / \mathrm{CeO}_{2}$ & $\mathrm{Pt} / \mathrm{ZrO}_{2}$ \\
\hline \multicolumn{5}{l}{ Humin derived products (wt\% on hunin intake) } \\
Alkylphenolics & 3.1 & 10.8 & 20.4 & \\
Aromatics & 5.0 & 7.5 & 0.9 & 1.5 \\
(Cyclic) alkanes & 1.5 & 3.0 & 4.6 & 0.2 \\
Total & 9.6 & 21.3 & 25.9 & 10.9
\end{tabular}

IPA derived products (wt\% on humin intake)

$\begin{array}{lllll}\text { Ketones/alcohols }^{b} & 43 & 43 & 37 & 15\end{array}$

${ }^{a}$ In wt\% based on humin intake. Conditions: $400{ }^{\circ} \mathrm{C}, 3$ h. ${ }^{b}$ Excluding acetone and IPA. 
$\mathrm{CeO}_{2}$, as is evident from the about 3 times higher amount of low molecular weight products derived from humins (Table 7). Whether this good performance is related to the average $\mathrm{Pt}$ nanoparticle size (very small particles observed for $\mathrm{Pt} / \mathrm{CeO}_{2}$ besides larger particles, see Fig. 7) or specifically related to the support structure (amongst others redox activity) needs to be investigated, e.g. by using humin model compounds. These studies are in progress and will be reported in due course.

\section{Conclusions}

In this paper, we have shown that it is possible to catalytically liquefy humins by a treatment in IPA at elevated temperatures using noble metal catalysts (Pt, Rh, Pd, Ru) on various supports. An initial screening study using carbon supports showed that $\mathrm{Pt}$ is the most promising catalyst when considering the humin conversion and composition of the liquid phase. Hydrogen, formed in situ by IPA dehydrogenation to acetone, is expected to play a key role and is an important reactant for subsequent hydrogenolysis and hydro(-deoxy)genation reactions of humins to low molecular weight humin derived compounds. The $\mathrm{Pt} / \mathrm{C}$ based catalyst performs best and shows a good balance between dehydrogenation activity (to form hydrogen) combined with hydrogenolysis/hydrodeoxygenation activity required to depolymerise the humin structure.

Analysis of the product mixture is hampered by the formation of significant amounts of aldol condensation products from acetone. However, using GCxGC and in combination with blank reactions in the absence of humins, it proved possible to identify that particularly low molecular weight alkylphenolics are formed from the humins, besides some aromatics. In addition, higher molecular weight species are present in the liquid product phase (GPC), likely humin oligomers.

Subsequent screening studies with Pt based catalyst on various inorganic supports show a clear support effect on humin conversion and the composition of the liquid phase. Particularly the ceria support shows promising results and good humin conversion is coupled with the formation of considerable amounts of alkylphenolics (up to $20 \%$ on humin intake).

Though a complex reaction mixture is obtained with product both from humins and the solvent, the development of efficient separation technology may allow the separation of the aldolcondensation products (like MIBK) and alkylphenolics from the mixture. Both component groups are existing, commercially available bulk chemicals with a high application range. For instance MIBK is used as a solvent whereas mixtures of alkylphenolics may be used as replacement of phenol in phenol based adhesive formulations. ${ }^{68}$ In addition, mixtures of alkylphenolics may also be used as biofuel blending agents to improve diesel engine performance. ${ }^{69,70}$

\section{Acknowledgements}

This research has been performed within the framework of the CatchBio program, project 053.70.732. The authors gratefully acknowledge the financial support of the Smart Mix program of the Ministry of Economic Affairs and the Netherlands Ministry of Education, Culture and Science.

\section{References}

1 D. J. Hayes, S. Fitzpatrick, M. H. B. Hayes and J. R. H. Ross, The Biofine Process - Production of Levulinic Acid, Furfural, and Formic Acid from Lignocellulosic Feedstocks, Wiley-VCH Verlag GmbH, 2008, ch. 7, pp. 139-164.

2 S. W. Fitzpatrick, Lignocellulose degradation to furfural and levulinic acid, US4897497A, 1990.

3 K. D. Baugh and P. L. McCarty, Biotechnol. Bioeng., 1988, 31, 50-61.

4 C. Zhou, X. Xia, C. Lin, D. Tong and J. Beltramini, Chem. Soc. Rev., 2011, 40, 5588-5617.

5 J. P. Lange, E. van der Heide, J. van Buijtenen and R. Price, ChemSusChem, 2012, 5, 150-166.

6 S. Ummartyotin and C. Pechyen, Renewable Sustainable Energy Rev., 2016, 62, 654-664.

7 K. J. Wu, Y. L. Wu, Y. Chen, H. Chen, J. L. Wang and M. D. Yang, ChemSusChem, 2016, 9, 1355-1385.

8 Z. Knez, E. Markocic, M. K. Hrncic, M. Ravber and M. Skerget, J. Supercrit. Fluids, 2015, 96, 46-52.

9 E. C. van der Pol, R. R. Bakker, P. Baets and G. Eggink, Appl. Microbiol. Biotechnol., 2014, 98, 9579-9593.

10 H. Rasmussen, H. R. Sorensen and A. S. Meyer, Carbohydr. Res., 2014, 385, 45-57.

11 R. A. Sheldon, Green Chem., 2014, 16, 950-963.

12 R. J. van Putten, J. C. van der Waal, E. de Jong, C. B. Rasrendra, H. J. Heeres and J. G. de Vries, Chem. Rev., 2013, 113, 1499-1597.

13 M. J. Biddy, C. Scarlata and C. Kinchin, Chemicals from Biomass: A Market Assessment of Bioproducts with Near-Term Potential, Energy Laboratory of The U.S. Department of Energy, 2016.

14 J. C. Serrano-Ruiz, R. M. West and J. A. Durnesic, Annu. Rev. Chem. Biomol. Eng., 2010, 1, 79-100.

15 P. Gallezot, Chem. Soc. Rev., 2012, 41, 1538-1558.

16 Z. Hu, S. Liu, Z. Yue, L. Yan, M. Yang and H. Yu, Environ. Sci. Technol., 2008, 42, 276-281.

17 S. K. Maity, Renewable Sustainable Energy Rev., 2015, 43, 1427-1445.

18 T. Werpy and G. Petersen, Top Value Added Chemicals form Biomass Volume I - Results of Screening for Potential Candidates from Sugars and Synthesis Gas, National Renewable Energy Laboratory (NREL), 2004.

19 B. Girisuta, L. P. B. M. Janssen and H. J. Heeres, Ind. Eng. Chem. Res., 2007, 46, 1696-1708.

20 B. Girisuta, L. P. B. M. Janssen and H. J. Heeres, Chem. Eng. Res. Des., 2006, 84, 339-349.

21 B. Girisuta, L. P. B. M. Janssen and H. J. Heeres, Green Chem., 2006, 8, 701-709.

22 B. D. Mullen, E. J. Molitor and A. K. Schrock, Oxidation of solids bio-char from levulinic acid processes, WO2015134349 A1, 2015.

23 E. J. Molitor and B. D. Mullen, Method of manufacturing dicarboxylic acids and derivatives from compositions comprising ketocarboxylic acids, EP2970078 A1, 2016. 
24 K. Yan, C. Jarvis, J. Gu and Y. Yan, Renewable Sustainable Energy Rev., 2015, 51, 986-997.

25 J. J. Bozell, L. Moens, D. C. Elliott, Y. Wang, G. G. Neuenscwander, S. W. Fitzpatrick, R. J. Bilski and J. L. Jarnefeld, Resour., Conserv. Recycl., 2000, 28, 227-239.

26 B. Girisuta, L. P. B. M. Janssen and H. J. Heeres, Chem. Eng. Res. Des., 2006, 84, 339-349.

27 I. van Zandvoort, Y. Wang, C. B. Rasrendra, E. R. H. van Eck, P. C. A. Bruijnincx, H. J. Heeres and B. M. Weckhuysen, ChemSusChem, 2013, 6, 1745-1758.

28 A. Funke and F. Ziegler, Biofuels, Bioprod. Biorefin., 2010, 4, 160-177.

29 M. Sevilla and A. B. Fuertes, Chem.-Eur. J., 2009, 15, 41954203.

30 M. Sevilla, J. A. Macia-Agullo and A. B. Fuertes, Biomass Bioenergy, 2011, 35, 3152-3159.

31 M. Sevilla and A. B. Fuertes, Carbon, 2009, 47, 2281-2289.

32 N. Baccile, G. Laurent, F. Babonneau, F. Fayon, M. M. Titirici and M. Antonietti, J. Phys. Chem. C, 2009, 113, 9644-9654.

33 I. Sumerskii, S. Krutov and M. Zarubin, Russ. J. Appl. Chem., 2010, 83, 320-327.

34 S. K. R. Patil and C. R. F. Lund, Energy Fuels, 2011, 25, 47454755.

35 I. van Zandvoort, E. J. Koers, M. Weingarth, P. C. A. Bruijnincx, M. Baldus and B. M. Weckhuysen, Green Chem., 2015, 17, 4383-4392.

36 T. M. C. Hoang, L. Lefferts and K. Seshan, ChemSusChem, 2013, 6, 1651-1658.

37 T. M. C. Hoang, E. R. H. van Eck, W. P. Bula, J. G. E. Gardeniers, L. Lefferts and K. Seshan, Green Chem., 2015, 17, 959-972.

38 C. B. Rasrendra, M. Windt, Y. Wang, S. Adisasmito, I. G. B. N. Makertihartha, E. R. H. van Eck, D. Meier and H. J. Heeres, J. Anal. Appl. Pyrolysis, 2013, 104, 299-307.

39 M. Trautmann, A. Lowe and Y. Traa, Green Chem., 2014, 16, 3710-3714.

40 M. Trautmann, S. Lang and Y. Traa, Fuel, 2015, 151, 102-109.

41 L. Lemee, L. Pinard, R. Beauchet and D. Kpogbemabou, Bioresour. Technol., 2013, 149, 465-469.

42 Y. Wang, S. Agarwal, A. Kloekhorst and H. J. Heeres, ChemSusChem, 2016, 9, 951.

43 A. Kloekhorst, J. Wildschut and H. J. Heeres, Catal. Sci. Technol., 2014, 4, 2367-2377.

44 Y. Ando, M. Yamashita and Y. Saito, Bull. Chem. Soc. Jpn., 2003, 76, 2045-2049.

45 Y. A. M. T. Ukisu, React. Kinet. Catal. Lett., 2004, 81, 305-311.
46 Y. Ukisu and T. Miyadera, React. Kinet. Catal. Lett., 2004, 81, 305-311.

47 M. Sakurai, H. Honda and H. Kameyama, Int. J. Hydrogen Energy, 2007, 32, 1303-1308.

48 A. Hinnen and J. Dreux, Bull. Soc. Chim. Fr., 1964, 1492-1498. 49 E. Sucharda and H. Kuczynski, Rocz. Chem., 1934, 14, 1182. 50 S. C. Luo and J. L. Falconer, J. Catal., 1999, 185, 393-407.

51 P. M. Reis, J. Silva, J. Da Silva and A. Pombeiro, J. Mol. Catal. A: Chem., 2004, 224, 189-195.

52 S. Smeds, T. Salmi and D. Y. Murzin, Appl. Catal., A, 1999, 185, 131-136.

53 C. B. Rasrendra, M. Windt, Y. Wang, S. Adisasmito, I. G. B. N. Makertihartha, E. R. H. van Eck, D. Meier and H. J. Heeres, J. Anal. Appl. Pyrolysis, 2013, 104, 299-307.

54 T. M. C. Hoang, PhD thesis, University of Twente, The Netherlands, 2015.

55 I. van Zandvoort, $\mathrm{PhD}$ thesis, Utrecht University, The Netherlands, 2015.

56 Y. T. Cheng and G. W. Huber, ACS Catal., 2011, 1, 611-628. 57 H. Iida and A. Igarashi, Appl. Catal., A, 2006, 298, 152-160.

58 I. Rekkab-Hammoumraoui, A. Choukchou-Braham, L. Pirault-Roy and C. Kappenstein, Bull. Mater. Sci., 2011, 34, 1127-1135.

59 T. Mitsui, K. Tsutsui, T. Matsui, R. Kikuchi and K. Eguchi, Appl. Catal., B, 2008, 78, 158-165.

60 K. A. S. K. Nagaoka, Catal. Lett., 2005, 99, 97-100.

61 Y. Chen, Z. Wang, Y. Zhang, J. Zhou and K. Cen, Int. J. Hydrogen Energy, 2010, 35, 445-451.

62 S. K. Meher, M. Cargnello, H. Troiani, T. Montini, G. R. Rao and P. Fornasiero, Appl. Catal., B, 2013, 130-131, 121-131.

63 M. Abid, G. Ehret and R. Touroude, Appl. Catal., A, 2001, 217, 219-229.

64 S. A. Singh and G. Madras, Appl. Catal., A, 2016, 518, 102114.

65 A. A. A. K. Maerle, Russ. J. Phys. Chem. A, 2016, 90, 1212-1216.

66 I. Krivtsov, L. Faba, E. Díaz, S. Ordóñez, V. Avdin, S. Khainakov and J. R. Garcia, Appl. Catal., A, 2014, 477, 26-33.

67 J. J. Nitz, Hydrolysis of the residues obtained in the production of isophorone to recover isophorone and acetone, US9035102 B2, 2015.

68 A. Effendi, H. Gerhauser and A. V. Bridgwater, Renewable Sustainable Energy Rev., 2008, 12, 2092-2116.

69 M. Boot, in Biofuels from Lignocellulosic Biomass: Innovations beyond Bioethanol, Wiley-VCH, 2016.

70 R. W. G. Van Haaren, PhD thesis, Technische Universiteit Eindhoven, The Netherlands2014. 